\title{
Association Between AST To ALT Ratio And Peripheral Artery Disease In Chinese Adults With Hypertension: A Cross-Sectional Study
}

Hui Liu

Nanchang University Second Affiliated Hospital of Nanchang University, Nanchang of Jiangxi,China Xiaoyuan Zha

Rancheng Community Health Service Center, Wuyuan of Jiangxi,China

\section{Congcong Ding}

Department of Cardiovascular Medicine, the Second Affiliated Hospital of Nanchang University, Nanchang of Jiangxi,China

\section{Lihua Hu}

Department of Cardiovascular Medicine, the Second Affiliated Hospital of Nanchang University,Nanchang of Jiangxi,China

\section{Minghui Li}

Department of Cardiovascular Medicine, the Second Affiliated Hospital of Nanchang University, Nanchang of Jiangxi,China

\section{Wei Zhou}

Center for Prevention and Treatment of Cardiovascular Diseases, the Second Affiliated Hospital of Nanchang University, Nanchang of Jiangxi,China

\section{Tao Wang}

Center for Prevention and Treatment of Cardiovascular Diseases, the Second Affiliated Hospital of Nanchang University, Nanchang of Jiangxi, China

\section{Lingjuan Zhu}

Center for Prevention and Treatment of Cardiovascular Diseases, the Second Affiliated Hospital of Nanchang University, Nanchang of Jiangxi, China

\section{Huihui Bao}

Center for Prevention and Treatment of Cardiovascular Diseases, the Second Affiliated Hospital of Nanchang University, Nanchang of Jiangxi,China

Xiaoshu Cheng ( $\square$ xiaoshumenfan126@163.com )

Nanchang University Second Affiliated Hospital https://orcid.org/0000-0001-7445-1988

\section{Research}

Keywords: AST / ALT ratio, peripheral artery disease, hypertensive, AST, ALT 
Posted Date: December 23rd, 2020

DOI: https://doi.org/10.21203/rs.3.rs-131080/v1

License: (c) (i) This work is licensed under a Creative Commons Attribution 4.0 International License. Read Full License 


\section{Abstract}

Background: Previous studies had shown that aspartate aminotransferase to alanine aminotransferase (AST/ALT ratio) plays a role in cardiovascular disease. Peripheral artery disease (PAD) is an important risk factor for cardiovascular disease. However, there are a little research on the association between the AST/ALT ratio and Peripheral artery disease (PAD).

Methods: A total of 10, 900 hypertensive patients from the Chinese Hypertension Registry Study were included in the final analysis. The association between AST / ALT and peripheral arterial disease (PAD), which was defined as $A B I \leq 0.9$ in either leg, was estimated by a multivariate logistic regression model.

Results: Overall, the prevalence of PAD was 3.21\%. After adjusting for potential confounders, AST / ALT ratio was independently and positively associated with the risk of PAD (OR: 1.31, 95\% Cl: 1.13 to 1.59), and a statistically significant increased risk of PAD for the third tertile (T3) of AST / ALT ratio compared to the first tertile (T1) (OR:1.49, 95\% Cl: 1.09 to 2.04 , $P$-trend= 0.005$)$ was found. Moreover, when the T1T2 group was combined into one group and used it as a reference group, the risk of PAD increased with the increase of AST/ALT and the risk ratio was 1.52 (95\% $\mathrm{Cl}: 1.20$ to 1.95$)$.

Conclusion: A higher AST/ALT ratio $(\geq 1.65)$ was associated with PAD risk in Chinese adults with hypertension. The presented results suggested that AST / ALT may help us highlight patients who are at high risk of vascular endpoints.

Trial registration: CHICTR, CHiCTR1800017274. Registered 20 July 2018.

\section{Introduction}

The incidence of arteriosclerosis cardiovascular disease is rapidly increasing as a result of the improvement in living standards, changes in diet and living habits in China. Peripheral artery disease (PAD), a kind of arteriosclerosis diseases, has become the third leading cause of arteriosclerosis cardiovascular morbidity next to stroke and coronary artery disease ${ }^{[1]}$. Smoking, diabetes, obesity, hypertension, dyslipidemia, aging and a family history of peripheral artery disease, heart disease are the risk factors for developing PAD ${ }^{[2]}$. Despite controlling these risk factors, the incidence rate of PAD is still high, whereas the awareness rate, treatment rate and control rate are low. According to an epidemiological study in China, the standardized prevalence rate of PAD was $6.6 \%$, the awareness rate was $4.9 \%$, the treatment rate was $1.9 \%$, and the control rate was $0.2 \%[3]$. Peripheral arterial disease has become a global health problem ${ }^{[4]}$, with high mortality and cardiovascular morbidity ${ }^{[4]}$. Hence, in addition to traditional risk factors, it is critical to find new markers that could predict PAD more easily and prevent cardiovascular death earlier ${ }^{[4]}$. A growing number of associations suggest assessing the value of new biomarkers in predicting risk of cardiovascular disease ${ }^{[10-12]}$.

Alanine aminotransferase (ALT) is mainly distributed in liver, followed by skeletal muscle, kidney, myocardium and other tissues. Aspartate aminotransferase (AST) is mainly distributed in myocardium, 
followed by liver, skeletal muscle and kidney. In hepatocytes, ALT is mostly present in the cytosol whereas AST in mitochondria. In most cases, the elevation of ALT and AST is consistent with the degree of hepatocyte damage, which are the most commonly used indicators of liver function. In the past, the AST/ALT ratio was often used to reflect a variety of liver-related diseases, such as alcoholic and nonalcoholic liver diseases ${ }^{[13]}$, autoimmune liver diseases ${ }^{[14]}$, and hepatitis $C^{[15]}$. Current findings emphasize that higher AST / ALT level can be biomarkers for cardiovascular diseases. For example, a prospective cohort conducted by Weng SF et al. consisting of 29,316 patients concluded that an increased AST / ALT ratio was more easily progressed to cardiovascular diseases in men ${ }^{[16]}$. Moreover, Yokoyama et al. demonstrated that AST / ALT ratio increased the risk of all-cause death and cardiovascular death by 1.43 times and 2.51 times respectively in a general population ${ }^{[17]}$. Considering that both the AST/ALT ratio and PAD were associated with cardiovascular disease and data on the relationship between AST/ALT ratio and PAD was limited, the aim of our study was to assess whether the AST / ALT ratio was associated with PAD.

\section{Materials And Methods}

\section{Study design and participants}

The present data came from the China Hypertension Registry Study (registration number: CHiCTR1800017274) whose main aim was to establish a national hypertension patient registry, to investigate the rate of incidence and control of hypertension in China. In addition, this observational study planned to evaluate the correlative factors that affect hypertension and its prognosis. Patients who were over 18 years older and had hypertension which was defined based on the usual $140 / 90 \mathrm{~mm} \mathrm{Hg}$, or reported a history of hypertension, or used anti-hypertensive drug(s) were eligible for enrolment. Patients who had psychological or nervous system impairment resulting in an inability to demonstrate informed consent, or were Unable to be followed-up according to the study protocol, or plans to relocate in the near future, or were not suitable for inclusion or long-term follow-up as assessed by the research doctor would be excluded. From March 2018 to August 2018, our team recruited 14,268 participants altogether in Wuyuan County, Shangrao City, Jiangxi Province, China. After excluding non-hypertensive, individuals with Ankle brachial index (ABI) date missing and AST/ALT date missing, 10,900 subjects included in the analysis finally.

This study complied with the principles of the Declaration of Helsinki and got approval by the Ethics Committee of the Institute of Biomedicine, Anhui Medical University. All participants were asked to sign an informed consent statement before enrollment.

\section{PAD}

Patients with resting $A B I \leq 0.9$ was diagnosed with $P A D^{[18]}$. After the patient remained at rest for 10 minutes, we measured the SBP of the brachial artery and dorsalis pedis or posterior tibial arteries using 
Omron Colin BP-203RPE III device (Omron, Kyoto, Japan), and then calculate the ABI by the ratio of the highest systolic pressure in the ankle to the highest systolic pressure in the arm ${ }^{[19]}$.

\section{Laboratory assays}

No fasting blood samples of all participants were gathered together in the next morning, frozen and sent to Biaojia Biotechnology Laboratory for analysis in Shenzhen, China. The core laboratory of the National Clinical Research Center for Kidney Disease (Guangzhou, China) undertaken the task of measuring biochemical indicators, such as fasting blood glucose (FBG), high-density lipoprotein cholesterol (HDL-C), total cholesterol (TC), triglycerides (TG), low-density lipoprotein-cholesterol (LDL-C), aspartate aminotransferases (AST) and alanine transaminase (ALT), total bilirubin (TBIL), $\gamma$-glutamyltransferase (GGT), albumin (ALB), uric acid (UA), homocysteine (Hcy), and creatinine using automatic clinical analyzers (Beckman Coulter). The glomerular filtration rate (eGFR) was estimated adopting the newly developed CKD-EPI equation ${ }^{[20]}$.

\section{Covariates}

At this baseline assessment, trained health professionals obtained the information about age, smoking, drinking, medical history (any hypertension, stroke, diabetes, hyperlipidemia and chronic kidney disease) and drug intake by questionnaire. Systolic blood pressure (SBP) and diastolic blood pressure (DBP) would be observed three times by electronic sphygmomanometers (Omron; Dalian, China) in the case of resting 10 minutes. Anthropometric indicators of height, weight, waist circumference and hip circumference were measured. Body mass index $\left(\mathrm{kg} / \mathrm{m}^{2}\right)$ was calculated by dividing body weight $(\mathrm{kg})$ by the square of height $(m)$.

\section{Statistical analysis}

For the purpose of investigating whether the AST / ALT ratio was related to PAD in selected participants, the statistical analysis included four main steps. First, mean \pm standard deviation represented continuous variables, and frequency (\%) represented categorical variables. Significant differences between the two groups were identified by the Mann-Whitney test. Second, logistic regression analysis models were employed to assess the association between AST/ALT ratio and PAD according to clinical importance, statistical significance in the univariable analysis, and potential confounding. Third, generalized additive model (GAM) and smooth curve fitting (penalized spline method) were conducted to describe the association between AST / ALT ratio and PAD clearly and concisely. Finally, subgroup analyses were performed to test the stability of the results.

All data analysis used R software version 4.0.3 (https://www.R-project.org) and Empower (R) version 3.0 (www.empowerstats.com). A two-sided $P<0.05$ was defined as significant differences.

\section{Results}


Table 1 listed the participants characteristics . In general, the mean years of age of the subjects was $63.86 \pm 9.25$, and males accounted for approximately $47.06 \%$. In our study, a total of 350 patients had peripheral arterial disease and the prevalence of PAD was $3.21 \%$. The prevalence of PAD increased with the increase of the AST/ALT ratio. Specifically, the prevalence rates in the first tertile, second tertile, and highest tertile were $2.36 \%, 2.51 \%$ and $4.76 \%$, respectively. Except for drinking, taking antiplatelet drugs, the history of stroke and CKD, other variables were significantly different between groups. Patients in the highest group (T3) tended to have a higher age, SBP and homocysteine, and had a lower BMI, DBP, FBG, $T C, T G$ and eGFR than those in the lowest group (T1). More subjects were smokers and had diabetes in the lowest group(T1). Moreover, the proportion of people who took antihypertensive drugs, lipid-lowering drugs, glucose-lowering drugs and anti-platelet drugs was lower in the highest group (T3). The characteristics were displayed by the status of PAD (no, yes) in Table S1. Compared with those who without PAD, patients with PAD had a higher levels of age, SBP, low-density lipoprotein, homocysteine, uric acid, AST/ALT ratio and smoking rates, and lower levels of BMI, eGFR, DBP, FBG and TG.

In this study, three models were generated to estimate the relationship between AST / ALT ratio and peripheral arterial disease(PAD). The adjusted ORs and 95\% confidence intervals (Cls) for PAD were presented in Table 2. When AST / ALT ratio was analyzed as a continuous variable in the crude model, for every one increase in AST / ALT ratio, the risk of PAD increased by 63\% (OR: 1.63, 95\% Cl: 1.42 to 1.88). After adjusting for sex, age, smoking, drinking, and BMI (Model 2), the risk of PAD increased by $41 \%$ as the AST / ALT ratio increased (OR:1.41, 95\% Cl: 1.20 to 1.64). In model 3 (adjusted completely), the risk of PAD increased by $34 \%$ (OR: 1.34, 95\% Cl: 1.13 to 1.59) with the increase of AST / ALT ratio. AST / ALT ratio was also converted to categorical variables (tertiles). The risks for PAD for participants in the second (1.24 to 1.65) and third tertiles ( $\geq 1.65$ ) were 0.96 (95\% Cl: 0.70 to 1.32 ) and 1.49 (95\% Cl: 1.09 to 2.04 ) respectively, when compared with those in tertile 1 . In view of the statistical significance of the $P$ value of the tertile 2, we combined T1-T2 into a group and used as a reference. A significantly higher risk of PAD (OR:1.53, 95\% Cl: $1.20,1.95)$ was found in participants in tertile $3(\geq 1.65)$ compared with participants in tertiles 1-2 ( 11.65$)$. Figure 1 clearly showed the relationship between AST/ALT and PAD with a curve clearly.

Further exploration of the impact of other variables on the association between AST/ALT and PAD was conducted. Figure 2 showed the results of subgroup analysis. There was no interactions discovered in the groups: sex (male, female), age ( $<60, \geq 65$ years), BMI ( $\left.\nabla 24 \mathrm{~kg} / \mathrm{m}^{2} \llbracket \geq 24 \mathrm{~kg} / \mathrm{m}^{2}\right)$, smoking (no, yes), drinking (no, yes), $\operatorname{HCY}(<15, \geq 15 \mu \mathrm{mol} / \mathrm{L})$ and $\operatorname{eGFR}\left(<90, \geq 90, \mathrm{ml} / \mathrm{min} / 1.73 \mathrm{~m}^{2}\right)$.

\section{Discussion}

This cross-sectional study among Chinese hypertensive population found that a higher AST / ALT ratio $(\geq 1.65$, tertile 3$)$ was significantly associated had a higher risk of PAD in comparison to lower AST/ALT ratio $(\mathbb{1} 1.65$, tertiles $1-2)$. The results remained stable after adjusting for other risk factors and suggested patients with elevated AST / ALT ratio may be a high risk subgroup of PAD. 
Previous studies have shown that AST/ALT ratio was associated with cardiovascular disease. For instance, Mohammed Ewid et al.conducted a study which evaluated the association between AST/ALT ratio and functional severity of chronic heart failure with reduced left ventricular ejection (HFREF), suggested that AST/ALT ratio of 0.9 was the best cut-off value to forecast left ventricular function status $^{[21]}$. At the same time, a study demonstrated that the best cut-off value of the AST / ALT ratio in predicting the cardiometabolism risk in was $1^{[21,22]}$. In addition $\mathbb{G}$ Gao $\mathrm{F}$ et al. analyzed the relationship between AST / ALT ratio and poor outcomes prognosis in patients with acute ischemic stroke ${ }^{[23]}$. The results showed that high AST / ALT was significantly associated with poor prognosis compared with those with low AST/ALT ratio. As can be seen from the above studies, the AST / ALT ratio does help to detect cardiovascular diseases. We all know that atherosclerosis is the root cause of most cardiovascular diseases ${ }^{[24]}$, and peripheral arterial disease is one of the main manifestations of atherosclerosis ${ }^{[25]}$. Since PAD was also related to cardiovascular morbidity and mortality and elevated AST/ALT ratio was associated with PAD in our study, which would be help us to screen more patients with latent diseases. The potential clinical value of AST/ALT ratio might be used to assess arteriosclerosis in the future. Moreover, the AST / ALT ratio is available, simpler and inexpensive compared to other methods.

To explain the results of this study, we conducted a Pub-Med search and the number of papers retrieved from the database was limited. A study based on individuals from the Japanese health check-up population who were between 24 to 84 years old and had no fatty liver analyzed the association of AST/ALT ratio with an indicator commonly used to assess atherosclerosis (Brachial ankle pulse wave velocity $(\mathrm{BaPWV}))^{[26]}$. It discovered a non-linear relationship between them. Specifically, AST/ALT ratio was correlated positively with BaPWV when AST/ALT (every 0.1 change) was greater than 13.1. Another study conducted by Peter et al. included 1782 patients who had been diagnosed with peripheral occlusive arterial disease, examined AST/ALT ratio as an influential factor for severe limb ischemia and an optimal cut-off value was identified. In a adjusted binary logistic regression model, patients with AST/ALT ratio > 1.67 had an high risk for critical limb ischemia (OR:2.0, 95\% Cl: 1.7-2.3) ${ }^{[26]}$. Combined with the results of the above two studies, we could conclude that AST / ALT ratio had a certain predictive value for cardiovascular disease, but the largest difference in these study was the cut-off value, which might be caused by the differences in study design, population, sample size, statistical analysis, etc. For clinical practice, this study suggested that we should pay attention not only to liver diseases, but also to cardiovascular diseases for people with elevated AST / ALT. It might provide an economic and effective tool for identifying high-risk individuals. In view of the lack of similar studies, however, the underlying mechanism is still obscure and the increase of AST / ALT ratio leading to insulin resistance and metabolic syndrome might the possible mechanism ${ }^{[28-30]}$.

\section{Strengths and Limitations}

As far as we know, this was the first study to report the relationship between AST / ALT ratio and PAD. Our advantages included large sample size, special hypertension population, reliable statistical analysis method and strict adjustment of confounding factors. Of course, some limitations needed to be noted. 
Firstly, our study was an analytical cross-sectional study, so it was difficult for us to determine the cause and effect. Second, the select of AST and ALT was the result of baseline measurement, and the influence of the dynamic changes of AST and ALT could not be ignored because of no multiple measurements. Third, due to the limitation of data, we could not distinguish the difference between AST/ALT and PAD in patients with and without liver disease. Last, considering that only Chinese patients with hypertension were included in the study population, it may not be suitable for other ethnic groups.

\section{Conclusions}

A higher ratio of AST/ALT ( $\geq 1.65$ ) was significantly associated with PAD risk in Chinese adults with hypertension. Our results suggested that AST / ALT may help us highlight patients who are at high risk of vascular endpoints.

\section{Abbreviations}

BMI body mass index; SUA serum uric acid; SBP systolic blood pressure; DBP diastolic blood pressure; FBG fasting blood glucose; TC total cholesterol; TG triglyceride; LDL-C low density lipoprotein cholesterol; HDL-C high density lipoprotein cholesterol; TBIL total bilirubin; DBIL direct bilirubin; GGT y-glutamyl transpeptidase; ALB albumin; HCY homocysteine; eGFR estimated glomerular filtration rate; PAD peripheral artery disease; CKD chronic kidney disease ; $A B I$ Ankle brachial index ; BaPWV Brachial ankle pulse wave velocity

\section{Declarations}

\section{Ethics approval and consent to participate}

The study was conducted in accordance with the Declaration of Helsinki and was approved by the Ethics Committee of the Anhui Medical University Biomedical Institute.

\section{Consent for publication}

Not applicable.

\section{Availability of data and materials}

Not applicable.

\section{Competing interests}

The authors declare that there is no conflict of interest.

\section{Funding}


This work was supported by the Science and Technology Innovation Platform Project of Jiangxi Province (Grant number: 20165BCD41005)

\section{Authors' Note}

$\mathrm{HL}$ wrote the manuscript and participated in the literature search, data analysis, and data interpretation. LHH extracted and collected data. XYZ, CCD, LHH, MHL, WZ, TW, LJZ conceived of the study and participated in its design and coordination. HHB and XSC participated in the study design and provided critical revision. All authors read and approved the final manuscript.

\section{Acknowledgement}

The authors thank all the participating authors for their contributions to this article.

\section{Reference}

[1] Fowkes FG, Rudan D, Rudan I, Aboyans V, Denenberg JO, McDermott MM, et al. Comparison of global estimates of prevalence and risk factors for peripheral artery disease in 2000 and 2010: a systematic review and analysis. Lancet, 2013,382(9901):1329-1340.

[2] Fowkes FG, Aboyans V, Fowkes FJ, McDermott MM, Sampson UK, Criqui MH. Peripheral artery disease: epidemiology and global perspectives. Nat Rev Cardiol, 2017,14(3):156-170.

[3] Wang Z, Wang X, Hao G, Chen Z, Zhang L, Shao L, et al. A national study of the prevalence and risk factors associated with peripheral arterial disease from China: The China Hypertension Survey, 20122015. Int J Cardiol, 2019,275:165-170.

[4] Song P, Rudan D, Zhu Y, Chen Z, Zhang L, Shao L, et al. Global, regional, and national prevalence and risk factors for peripheral artery disease in 2015: an updated systematic review and analysis. Lancet Glob Health, 2019,7(8):e1020-e1030.

[5] Golomb BA, Dang TT, Criqui MH. Peripheral arterial disease: morbidity and mortality implications. Circulation, 2006,114(7):688-699.

[6] Cesaro A, Schiavo A, Moscarella E, Coletta S₫Conte M $₫$ Gragnano F, et al. Lipoprotein(a): a genetic marker for cardiovascular disease and target for emerging therapies. J Cardiovasc Med (Hagerstown), 2020.

[7] Cesaro A, Bianconi V, Gragnano F, Moscarella E, Fimiani F, Monda E, et al. Beyond cholesterol metabolism: The pleiotropic effects of proprotein convertase subtilisin/kexin type 9 (PCSK9). Genetics, mutations, expression, and perspective for long-term inhibition. Biofactors, 2020,46(3):367-380.

[8] Calabro P, Gragnano F, Golia E, Grove EL. Von Willebrand Factor and Venous Thromboembolism: Pathogenic Link and Therapeutic Implications. Semin Thromb Hemost, 2018,44(3):249-260. 
[9] Gragnano F, Golia E, Natale F, Bianchi R, Pariggiano I, Crisci M, et al. Von Willebrand Factor and Cardiovascular Disease: From a Biochemical Marker to an Attractive Therapeutic Target. Curr Vasc Pharmacol, 2017,15(5):404-415.

[10] Helfand M, Buckley D I, Freeman M, Fu R, Rogers K, Fleming C, et al. Emerging risk factors for coronary heart disease: a summary of systematic reviews conducted for the U.S. Preventive Services Task Force. Ann Intern Med, 2009,151(7):496-507.

[11] Stone NJ, Robinson JG, Lichtenstein AH, Bairey Merz CN, Blum CB, Eckel RH, et al. 2013 ACC/AHA guideline on the treatment of blood cholesterol to reduce atherosclerotic cardiovascular risk in adults: a report of the American College of Cardiology/American Heart Association Task Force on Practice Guidelines. J Am Coll Cardiol, 2014,63(25 Pt B):2889-2934.

[12] Joint British Societies' consensus recommendations for the prevention of cardiovascular disease (JBS3). Heart, 2014,100 Suppl 2:i1-i67.

[13] Nyblom H, Berggren U, Balldin J, Olsson R. High AST/ALT ratio may indicate advanced alcoholic liver disease rather than heavy drinking. Alcohol Alcohol, 2004,39(4):336-339.

[14] Nyblom H, Nordlinder $\mathrm{H}$, Olsson R. High aspartate to alanine aminotransferase ratio is an indicator of cirrhosis and poor outcome in patients with primary sclerosing cholangitis. Liver Int, 2007,27(5):694-699.

[15] Giannini E, Risso D, Botta F, Chiarbonello B, Fasoli A, Malfatti F, et al. Validity and clinical utility of the aspartate aminotransferase-alanine aminotransferase ratio in assessing disease severity and prognosis in patients with hepatitis C virus-related chronic liver disease. Arch Intern Med, 2003,163(2):218-224.

[16] Weng SF, Kai J, Guha IN, Qureshi N. The value of aspartate aminotransferase and alanine aminotransferase in cardiovascular disease risk assessment. Open Heart, 2015,2(1):e272.

[17] Yokoyama M, Watanabe T, Otaki Y, Takahashi H, Arimoto T, Shishido T, et al. Association of the Aspartate Aminotransferase to Alanine Aminotransferase Ratio with BNP Level and Cardiovascular Mortality in the General Population: The Yamagata Study 10-Year Follow-Up. Dis Markers, 2016,2016:4857917.

[18] Dachun X, Jue L, Liling Z, Yawei Xu, Dayi Hu, Pagoto SL, et al. Sensitivity and specificity of the anklebrachial index to diagnose peripheral artery disease: a structured review. Vasc Med, 2010,15(5):361-369.

[19] Gerhard-Herman MD, Gornik HL, Barrett C, Barshes NR囚Corriere MA囚Drachman DE, et al. 2016 AHA/ACC Guideline on the Management of Patients With Lower Extremity Peripheral Artery Disease: Executive Summary: A Report of the American College of Cardiology/American Heart Association Task Force on Clinical Practice Guidelines. Circulation, 2017,135(12):e686-e725.

[20] Levey AS, Stevens LA, Schmid CH, Zhang YL, Castro AF Rd, Feldman HI, et al. A new equation to estimate glomerular filtration rate. Ann Intern Med, 2009,150(9):604-612. 
[21] Ewid M, Sherif H, Allihimy A S, Alharbi SA, Aldrewesh DA, Alkuraydis SA, et al. AST/ALT ratio predicts the functional severity of chronic heart failure with reduced left ventricular ejection fraction. BMC Res Notes, 2020,13(1):178.

[22] Long MT, Pedley A, Massaro JM, Hoffmann U, Fox CS. The Association between Non-Invasive Hepatic Fibrosis Markers and Cardiometabolic Risk Factors in the Framingham Heart Study. PLoS One, 2016,11(6):e157517.

[23] Gao F, Chen C, Lu J, Zheng J, Ma XC, Yuan XY, et al. De Ritis ratio (AST/ALT) as an independent predictor of poor outcome in patients with acute ischemic stroke.Neuropsychiatr Dis Treat, 2017,13:15511557.

[24] Schiano V, Sirico G, Giugliano G, Laurenzano E, Brevetti L, Perrino C, et al. Femoral plaque echogenicity and cardiovascular risk in claudicants. JACC Cardiovasc Imaging, 2012,5(4):348-357.

[25] Meijer WT, Hoes AW, Rutgers D, Bots ML, Hofman A, Grobbee DE. Peripheral arterial disease in the elderly: The Rotterdam Study. Arterioscler Thromb Vasc Biol, 1998,18(2):185-192.

[26] Liu Y, Zhao P, Cheng M, Yu LखCheng Z『Fan L, et al. AST to ALT ratio and arterial stiffness in non-fatty liver Japanese population:a secondary analysis based on a cross-sectional study. Lipids Health Dis, 2018,17(1):275.

[27] Rief P, Pichler M, Raggam R, Hafner F, Gerger A, Eller P, et al. The AST/ALT (De-Ritis) ratio: A novel marker for critical limb ischemia in peripheral arterial occlusive disease patients. Medicine (Baltimore), 2016,95(24):e3843.

[28] Dessein PH, Woodiwiss AJ, Joffe BI, Norton GR, et al. Aminotransferases are associated with insulin resistance and atherosclerosis in rheumatoid arthritis. BMC Cardiovasc Disord, 2007,7:31.

[29] Hanley A J, Williams K, Festa A, Wagenknecht LE, D'Agostino RB Jr, Haffner SM. Liver markers and development of the metabolic syndrome: the insulin resistance atherosclerosis study. Diabetes, 2005,54(11):3140-3147.

[30] Yadav D, Choi E, Ahn S V, Baik SK, Cho YZ, Koh SB, et al. Incremental Predictive Value of Serum ASTto-ALT Ratio for Incident Metabolic Syndrome: The ARIRANG Study. PLoS One, 2016,11(8):e161304.

\section{Tables}


Table 1囚Baseline characteristics of participants stratified by tertiles of AST/ALT ratio.

\begin{tabular}{|c|c|c|c|c|c|}
\hline AST/ALT ratio & Total & $\begin{array}{l}\text { Tertile } 1 \\
\leq 1.23\end{array}$ & $\begin{array}{l}\text { Tertile } 2 \\
(1.24-1.65)\end{array}$ & $\begin{array}{l}\text { Tertile } 3 \\
(\geq 1.65)\end{array}$ & $\begin{array}{l}P \text { - } \\
\text { value }\end{array}$ \\
\hline $\mathrm{N}$ & 10900 & 3595 & 3669 & 3636 & \\
\hline Male & $\begin{array}{l}5129 \\
(47.06 \%)\end{array}$ & $\begin{array}{l}1955 \\
(54.38 \%)\end{array}$ & $\begin{array}{l}1591 \\
(43.36 \%)^{a}\end{array}$ & $\begin{array}{l}1583 \\
(43.54 \%)^{b}\end{array}$ & $<0.001$ \\
\hline AGE (years) & $63.86 \pm 9.25$ & $60.11 \pm 8.67$ & $63.87 \pm 8.47^{a}$ & $\begin{array}{l}67.55 \pm 9.08 \\
\text { bc }\end{array}$ & $<0.001$ \\
\hline Current smoking & $\begin{array}{l}2868 \\
(26.31 \%)\end{array}$ & $\begin{array}{l}1026 \\
(28.55 \%)\end{array}$ & $\begin{array}{l}868(23.66 \%) \\
a\end{array}$ & 974 (26.79\%) & $<0.001$ \\
\hline Current drinking & $\begin{array}{l}2469 \\
(22.66 \%)\end{array}$ & $\begin{array}{l}820 \\
(22.82 \%)\end{array}$ & 794 (21.64\%) & $855(23.51 \%)$ & 0.154 \\
\hline BMI (kg/m2) & $23.59 \pm 3.81$ & $25.34 \pm 4.14$ & $23.48 \pm 3.24^{a}$ & $\begin{array}{l}21.96 \pm 3.21 \\
b c\end{array}$ & $<0.001$ \\
\hline mean SBP (mmHg ) & $\begin{array}{l}148.48 \pm \\
17.79\end{array}$ & $\begin{array}{l}147.37 \pm \\
16.98\end{array}$ & $\begin{array}{l}148.72 \pm \\
17.76^{a}\end{array}$ & $\begin{array}{l}149.33^{ \pm} \\
18.52^{b}\end{array}$ & $<0.001$ \\
\hline mean DBP $(\mathrm{mmHg})$ & $\begin{array}{l}89.02 \pm \\
10.74\end{array}$ & $\begin{array}{l}91.00 \pm \\
10.33\end{array}$ & $\begin{array}{l}88.96 \pm 10.54 \\
a\end{array}$ & $\begin{array}{l}87.12 \pm 11.00 \\
b c\end{array}$ & $<0.001$ \\
\hline $\mathrm{FBG}, \mathrm{mmol} / \mathrm{L}$ & $6.17 \pm 1.60$ & $6.62 \pm 2.14$ & $6.07 \pm 1.30^{a}$ & $5.82 \pm 1.07^{b c}$ & $<0.001$ \\
\hline $\mathrm{TC}, \mathrm{mmol} / \mathrm{L}$ & $5.14 \pm 1.11$ & $5.22 \pm 1.17$ & $5.18 \pm 1.08$ & $5.04 \pm 1.08 b c$ & $<0.001$ \\
\hline TG,mmol/L & $1.78 \pm 1.25$ & $2.17 \pm 1.53$ & $1.73 \pm 1.07^{a}$ & $1.45 \pm 0.97^{b c}$ & $<0.001$ \\
\hline LDL-C,mmol/L & $2.99 \pm 0.81$ & $3.13 \pm 0.84$ & $3.00 \pm 0.78^{a}$ & $2.84 \pm 0.78 b c$ & $<0.001$ \\
\hline $\mathrm{HDL}-\mathrm{C}, \mathrm{mmol} / \mathrm{L}$ & $1.59 \pm 0.44$ & $1.48 \pm 0.38$ & $1.60 \pm 0.43^{a}$ & $1.69 \pm 0.47^{b}$ & $<0.001$ \\
\hline TBIL,$\mu \mathrm{mol} / \mathrm{L}$ & $14.66 \pm 6.86$ & $14.97 \pm 6.57$ & $14.47 \pm 6.15^{\mathrm{a}}$ & $14.54 \pm 7.75^{b}$ & 0.004 \\
\hline $\mathrm{DBIL}, \mu \mathrm{mol} / \mathrm{L}$ & $5.61 \pm 2.66$ & $5.60 \pm 2.22$ & $5.52 \pm 2.07$ & $5.71 \pm 3.46^{c}$ & 0.011 \\
\hline GGT,U/L & $\begin{array}{l}33.03 \pm \\
42.61\end{array}$ & $\begin{array}{l}44.48 \pm \\
50.24\end{array}$ & $\begin{array}{l}28.77 \pm 34.43 \\
a\end{array}$ & $\begin{array}{l}26.02 \pm 39.44 \\
b c\end{array}$ & $<0.001$ \\
\hline ALB,g/L & $46.80 \pm 4.16$ & $47.38 \pm 4.06$ & $46.86 \pm 3.99 \mathrm{a}$ & $\begin{array}{l}46.18 \pm 4.34 \\
\text { bc }\end{array}$ & $<0.001$ \\
\hline $\mathrm{UA}, \mathrm{mg} / \mathrm{dL}$ & $6.98 \pm 2.03$ & $7.30 \pm 2.08$ & $6.86 \pm 1.96^{a}$ & $6.77 \pm 2.01 \mathrm{bc}$ & $<0.001$ \\
\hline $\mathrm{Hcy}, \mu \mathrm{mol} / \mathrm{L}$ & $\begin{array}{l}18.00 \pm \\
11.04\end{array}$ & $\begin{array}{l}17.33 \pm \\
11.08\end{array}$ & $17.71 \pm 10.73$ & $\begin{array}{l}18.95 \pm 11.23 \\
b c\end{array}$ & $<0.001$ \\
\hline
\end{tabular}




\begin{tabular}{|c|c|c|c|c|c|}
\hline $\mathrm{eGFR}, \mathrm{ml} / \mathrm{min} / 1.73 \mathrm{~m} 2$ & $\begin{array}{l}88.67 \pm \\
20.38\end{array}$ & $\begin{array}{l}92.16 \pm \\
20.26\end{array}$ & $\begin{array}{l}89.13 \pm 19.60 \\
a\end{array}$ & $\begin{array}{l}84.75 \pm 20.58 \\
\text { bc }\end{array}$ & $<0.001$ \\
\hline PAD & $350(3.21 \%)$ & $85(2.36 \%)$ & $92(2.51 \%)$ & $173(4.76 \%)$ bc & $<0.001$ \\
\hline \multicolumn{6}{|l|}{ Medical history(n,\%) } \\
\hline Diabetes & $\begin{array}{l}1978 \\
(18.15 \%)\end{array}$ & $\begin{array}{l}1002 \\
(27.87 \%)\end{array}$ & $\begin{array}{l}584(15.92 \%) \\
a\end{array}$ & $\begin{array}{l}392(10.78 \%) \\
b c\end{array}$ & $<0.001$ \\
\hline Stroke & 708 (6.50\%) & 247 (6.87\%) & $239(6.51 \%)$ & $222(6.11 \%)$ & 0.418 \\
\hline CKD & $538(4.94 \%)$ & $183(5.09 \%)$ & $177(4.82 \%)$ & $178(4.90 \%)$ & 0.864 \\
\hline Dyslipidemia & $\begin{array}{l}1536 \\
(14.09 \%)\end{array}$ & $\begin{array}{l}731 \\
(20.33 \%)\end{array}$ & $\begin{array}{l}481(13.11 \%) \\
\mathrm{a}\end{array}$ & $324(8.91 \%) b c$ & $<0.001$ \\
\hline \multicolumn{6}{|l|}{ Mediciation use,n(\%) } \\
\hline $\begin{array}{l}\text { Antihypertensive } \\
\text { drugs }\end{array}$ & $\begin{array}{l}7155 \\
(65.65 \%)\end{array}$ & $\begin{array}{l}2456 \\
(68.34 \%)\end{array}$ & $\begin{array}{l}2394 \\
(65.25 \%)^{a}\end{array}$ & $\begin{array}{l}2305(63.39 \%) \\
b\end{array}$ & $<0.001$ \\
\hline $\begin{array}{l}\text { Glucose-lowering } \\
\text { drugs }\end{array}$ & $572(5.25 \%)$ & 331 (9.21\%) & $158(4.31 \%)^{a}$ & $83(2.28 \%) b c$ & $<0.001$ \\
\hline Lipid-lowering drugs & $381(3.50 \%)$ & 167 (4.65\%) & $127(3.46 \%)^{a}$ & $87(2.39 \%) b c$ & $<0.001$ \\
\hline Antiplatelet drugs & 429 (3.94\%) & $162(4.51 \%)$ & $143(3.90 \%)^{a}$ & $124(3.41 \%) b$ & 0.056 \\
\hline
\end{tabular}

Values of continuous variables are presented as mean $\pm S D$, categorical variables are presented as $\mathrm{n}(\%)$

Abbreviations: $B M I$ body mass index, SUA serum uric acid, $S B P$ systolic blood pressure, $D B P$ diastolic blood pressure, $\boldsymbol{F B G}$ fasting blood glucose, $\boldsymbol{T C}$ total cholesterol, $\boldsymbol{T} \boldsymbol{G}$ triglyceride, $\boldsymbol{L D L}$ Clow density lipoprotein, $H D L-C$ high density lipoprotein cholesterol,TBIL total bilirubin, DBIL direc tbilirubin, $G G T$ glutamyltransferase, $\boldsymbol{A L B}$ albumin, $U A$ uric acid, $\boldsymbol{H C Y}$ homocysteine; eGFR:estimated glomerular filtration rate, $P A D$ peripheral artery disease, $C K D$ chronic kidney disease

a indicates a significant difference between $\mathrm{T} 2$ and $\mathrm{T} 1, \mathrm{P}<0.05{ }^{\mathrm{b}}$ indicates a significant difference between $\mathrm{T} 3$ and $\mathrm{T} 1, \mathrm{P}<0.05 ;{ }^{\mathrm{C}}$ indicates a significant difference between $\mathrm{T} 3$ and $\mathrm{T} 1, \mathrm{P}<0.05$ 


\begin{tabular}{|c|c|c|c|c|c|c|}
\hline & Model 1 & & Model 2 & & Model 3 & \\
\hline $\begin{array}{l}\text { AST/ALT } \\
\text { ratio }\end{array}$ & $\mathrm{OR}(95 \% \mathrm{Cl})$ & $P$ & $\mathrm{OR}(95 \% \mathrm{Cl})$ & $P$ & $\mathrm{OR}(95 \% \mathrm{Cl})$ & $P$ \\
\hline Continuous & $\begin{array}{l}1.63(1.42, \\
1.88)\end{array}$ & $<0.001$ & $\begin{array}{l}1.41(1.20 \\
1.65)\end{array}$ & $<0.001$ & $\begin{array}{l}1.34(1.13 \\
1.59)\end{array}$ & 0.001 \\
\hline \multicolumn{7}{|l|}{ Tertiles } \\
\hline $\mathrm{T} 1(\leq 1.23)$ & Reference & & Reference & & Reference & \\
\hline $\begin{array}{l}\text { T2(1.24- } \\
1.65)\end{array}$ & $\begin{array}{l}1.06(0.79 \\
1.43)\end{array}$ & 0.693 & $\begin{array}{l}0.92(0.68 \\
1.26)\end{array}$ & 0.607 & $\begin{array}{l}0.96(0.70 \\
1.32)\end{array}$ & 0.801 \\
\hline $\mathrm{T} 3(\geq 1.65)$ & $\begin{array}{l}2.06(1.58 \\
2.69)\end{array}$ & 0.350 & $\begin{array}{l}1.52 \\
2.04)\end{array}$ & 0.005 & $\begin{array}{l}1.49(1.09 \\
2.04)\end{array}$ & 0.012 \\
\hline$P$ for trend & & $<0.0001$ & & 0.001 & & 0.005 \\
\hline \multicolumn{7}{|l|}{ Categories } \\
\hline T1-T2(『1.65) & Reference & & Reference & & Reference & \\
\hline $\mathrm{T} 3(\geq 1.65)$ & $\begin{array}{l}2.00(1.62 \\
2.48)\end{array}$ & $<0.0001$ & $\begin{array}{l}1.60(1.27 \\
2.01)\end{array}$ & $<0.0001$ & $\begin{array}{l}1.53(1.20 \\
1.95)\end{array}$ & $<0.0006$ \\
\hline \multicolumn{7}{|c|}{ Model 1: adjusted for none. } \\
\hline \multicolumn{7}{|c|}{ Model 2: adjusted for age, gender, smoking,drinking, BMI. } \\
\hline \multicolumn{7}{|c|}{$\begin{array}{l}\text { Model 3: adjusted for age, gender, smoking,drinking, BMl;SBP; DBP; TC;TG; LDL-C;HDL- } \\
\text { C;FBG;GGT;TBIL;DBIL;ALB;UA;Hcy;eGFR;diabetes; antihypertensive drugs; Glucose-lowering } \\
\text { drugs;Lipid-lowering drugs. }\end{array}$} \\
\hline
\end{tabular}

\section{Figures}




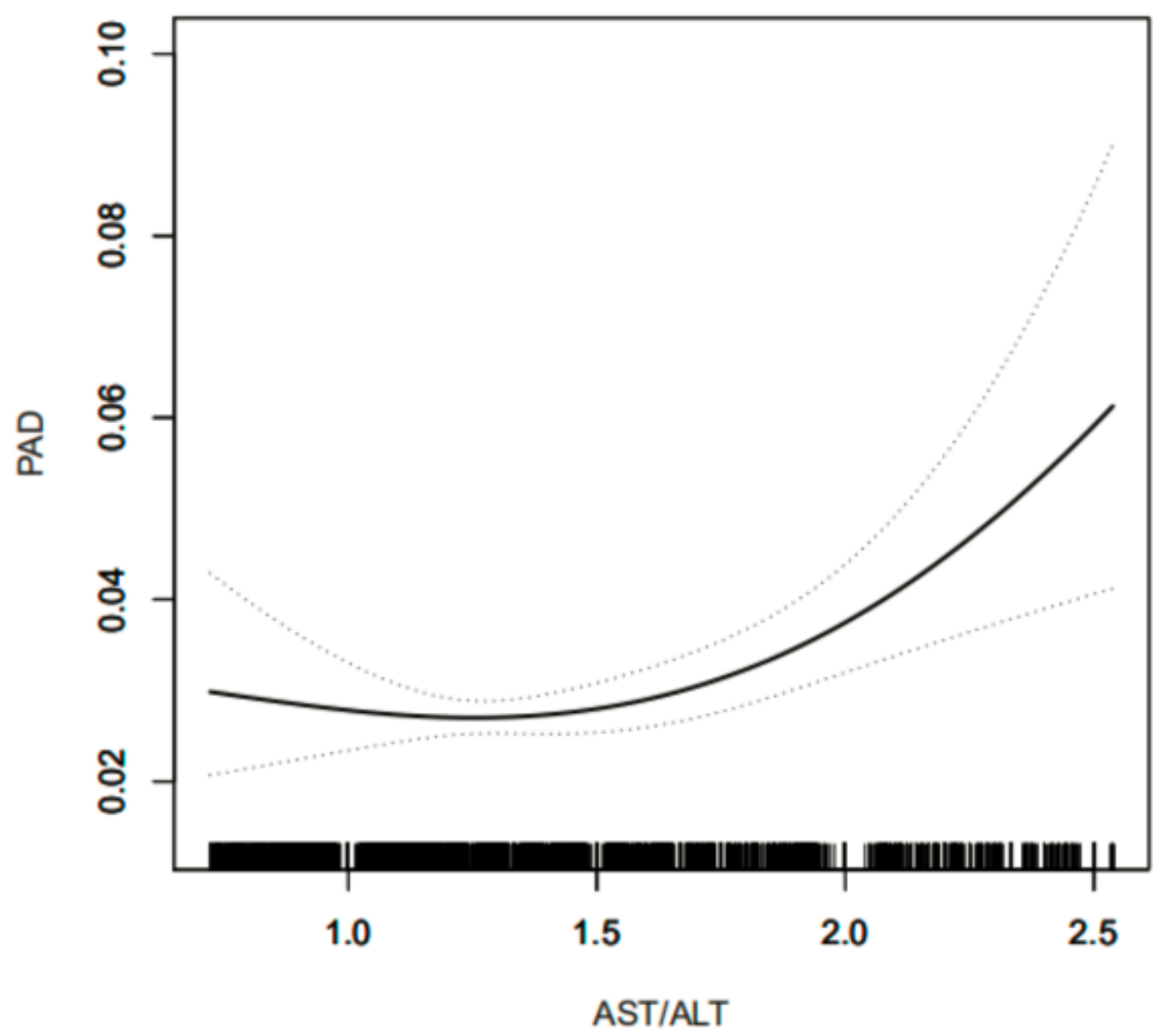

Figure 1

Association between AST/ALT ratio and peripheral arterial disease (PAD) adjusted for age, sex, smoking, drinking, BMI, SBP, DBP, TC,TG, LDL-C, HDL-C, FBG, GGT, TBIL, DBIL, ALB, UA, Hcy, eGFR, diabetes, antihypertensive drugs, glucose-lowering drugs and Lipid-lowering drugs. 


\begin{tabular}{|c|c|c|c|c|}
\hline Subgroup & Events $(\%)$ & OR( $(95 \%$ CI $)$ & & $P$ for interac \\
\hline Sex & & & & 0.363 \\
\hline male & $194(55.4 \%)$ & $1.69(1.21,2.35)$ & & \\
\hline female & $156(44.6 \%)$ & $1.34(0.93,1.93)$ & & \\
\hline Age,years & & & & 0.515 \\
\hline$<65$ & $80(22.9 \%)$ & $1.27(0.73,2.23)$ & & \\
\hline$\geq 65$ & $270(77.1 \%)$ & $1.57(1.19,2.07)$ & - & \\
\hline Current Smoking & & & & 0.657 \\
\hline Yes & $140(40.0 \%)$ & $1.63(1.10,2.42)$ & 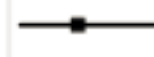 & \\
\hline No & $210(60.0 \%)$ & $1.46(1.07,1.99)$ & & \\
\hline Current Drinking & & & & 0.62 \\
\hline Yes & $69(19.7 \%)$ & $1.35(0.77,2.37)$ & & \\
\hline No & $281(80.3 \%)$ & $1.56(1.19,2.05)$ & & \\
\hline BMI,kg/m2 & & & & 0.283 \\
\hline$<24$ & $235(67.1 \%)$ & $1.67(1.25,2.23)$ & & \\
\hline$\geq 24$ & $115(32.9 \%)$ & $1.24(0.78,1.97)$ & & \\
\hline $\mathrm{eGFR}, \mathrm{ml} / \mathrm{min} / 1.73 \mathrm{~m} 2$ & & & & 0.911 \\
\hline$<90$ & $229(65.4 \%)$ & $1.57(1.16,2.12)$ & $\rightarrow$ & \\
\hline$\geq 90$ & $121(34.6 \%)$ & $1.51(0.99,2.30)$ & & \\
\hline Hcy,umol/L & & & & 0.299 \\
\hline$<15$ & $116(33.14 \%)$ & $1.84(1.20,2.84)$ & & \\
\hline \multirow[t]{3}{*}{$\geq 15$} & $234(66.86 \%)$ & $1.42(1.05,1.91)$ & $\rightarrow-$ & \\
\hline & & & $T$ & \\
\hline & & & 2 & 3 \\
\hline
\end{tabular}

\section{Figure 2}

Association between AST/ALT (T3 vs. T1-T2) and PAD in various subgroups. The models adjusted for age, sex, smoking, drinking, BMI, SBP, DBP, TC,TG, LDL-C, HDL-C, FBG, GGT, TBIL, DBIL, ALB, UA, Hcy, eGFR, diabetes, anti-hypertensive drugs, glucose-lowering drugs and Lipid-lowering drugs, except for the stratify.

\section{Supplementary Files}

This is a list of supplementary files associated with this preprint. Click to download.

- SupplementaryTable1.doc 